\title{
Determination of the working time requirement for suckling sows in the pen of Wels
}

\author{
E. Quendler'1, P. Pötz'1, W. Hagmüller², R. Kogler'1, J. Boxberger ${ }^{1}$ \\ ${ }^{1}$ Universität für Bodenkultur, Wien; ${ }^{2}$ LFZ Raumberg-Gumpenstein, Wels Thalheim, Austria
}

\begin{abstract}
These days, especially in organic piglet production, it is necessary to reduce the production costs to be competitive on the market. A large proportion of the production costs are caused by labor and construction costs to ensure a high level of animal welfare. The farrowing pen of Wels, currently existing in prototype form, was designed to fulfill organic farming requirements, improve animal welfare, and minimize the costs for construction and labor. The housing system is characterized by four separate functional areas: the lying area, the excretion and moving area, the feeding area for the sow, and a piglet nest. To identify the working time requirements of routine and special tasks, a time study, based on the work element method and an electronic time recording system (ortim b3) (a Pocket PC with time recording software), was conducted. The influencing variables and the time measurements were collected by directly observing work processes in the farrowing unit, which had 5 farrowing pens, over a period of 21 days at the "LFZ Raumberg Gumpenstein." The data were descriptive and statistically analyzed to obtain planning data on the element basis. The time requirement was modeled according to the related task and in total over the suckling period. The routine tasks consisted in transporting the feed to the pen, feeding the sows, monitoring the sows and piglets, mucking out the dung corridor with a tractor and sprinkling straw in it, as well as filling up the hay rack. The labor input was 3.99 AKmin per sow and day in total. The special tasks included inoculating the piglets, marking with ear tags, castrating the male piglets, cleaning the whole pen and the dung corridor, and preparing the farrowing pen for the next sows. Special work required 25.9 MPmin per sow over the keeping period of 21 days. The total working time requirements over the period of 21 days were $1.82 \mathrm{MPh}$ per sow. Overall, the farrowing pen of Wels has low time requirements and can be seen as a good alternative to the existing organic pens.
\end{abstract}

Correspondence: Elisabeth Quender, UniversitätfürBodenkultur, Peter Jordan Straße 82, 1190 Wien, Austria

E-mail: elisabeth.quendler@boku.ac.at

Key words: Farrowing pen of Wels, organic piglet production, working time requirements

(C) Copyright E. Quendler et al., 2013

Licensee PAGEPress, Italy

Journal of Agricultural Engineering 2013; XLIV(s2):e128

doi:10.4081/jae.2013.s2.e128

This article is distributed under the terms of the Creative Commons Attribution Noncommercial License (by-nc 3.0) which permits any noncommercial use, distribution, and reproduction in any medium, provided the original author(s) and source are credited.

\section{Introduction}

The organic piglet production is currently facing major challenges. Consumers are demanding that sows and piglets are kept in animalfriendly systems, maintaining a high degree of animal welfare and avoiding keeping suckling sows in farrowing crate systems, which do not allow natural movement of the sow and do not meet her natural basic needs, such as her nesting behavior. The different de sign of farrowing systems leads to differences in labor requirements and hence to significant differences in the cost of production (Weber et al., 1996). Animal-friendly systems are more costly in construction and management than conventional farrowing crate systems. Due to enhanced space with straw bedding, there exist higher resource utilization and sometimes higher piglet losses by crushing (Quen dler et al., 2010). These additional investment costs are exacerbated by rising energy and commodity prices, tighter funding conditions, difficult marketing channels for organic piglets and stagnant meat prices. Consequences for farm managers are closing down, especially of small farms, or the change to profitable niche products and the reduction of production costs by growth in order to remain in p roduction. For example, since 1995 the number of pig farmers in Austria has fallen by $74.2 \%$; on a daily basis about 15 farms have given up pig production (Statistik Austria, 2012).The production cost reduction can be achieved through efficient use of resources, high level of performance and growth (Quendler et al., 2010). For organic piglet production, the FAT2 pen, which involves higher total prod uction costs per piglet (by $18.3 \%$ ) than conventional farrowing crate systems, is predominantly chosen (Quendler et al., 2010). The positioning of the feed trough near the lying area results in an accumulation of food residues in the resting area. The sow uses the outlet as an additional excretion area. This results in additional cleaning activities which contribute to a higher labor requirement. To elim inate these weaknesses, the pen of Wels, which is currently in a prototype stage, has been developed for organic piglet production (Hagmüller et al., 2010). The design of the pen of Wels aims to lower construction costs and fulfill ethological needs of sows. To which extent an optimization has been achieved can only be confirmed by comparison of processing key data. The difficulty of the comparison li es in the missing availability of data for the pen of Wels. To fulfill these objectives processing key data must be collected. For this reason, the determination of the working time requirements for the pen of Wels, based on the work element method, was the aim of this study.

\section{Materials and methods}

\section{Experimental farm and pen of wels}

The study was carried out in the research center Raumberg Gumpenstein, which is located in Wels (Austria). During the survey, 34 sows were kept and production was done according to the "in-out" method. The farrowing pen of Wels was developed and optimized 
according to the requirements of the current EC Organic Regulation 834/2007 (Hagmüller et al., 2010). It consists of a concrete slab; the interior walls are made of three-layer plates $(58 \mathrm{~mm})$ while the outlet walls are made of galvanized steel and PVC panels. The lying area is separate from the run-out, manure and feeding area and can be completely closed with an insulating cover. In winter, the lid serves to maintain an optimal temperature of the lying area. The door to the outlet has a suspension system that automatically closes after leaving the pen, so that the temperature in the resting area cannot drop sharply. The piglets can leave the bay via the piglet slip and reach the exit. The piglet net has an area of $1.1 \mathrm{~m}^{2}$, is locked with a grafter above the control corridor, mulched with straw and heated with a hotplate from above. The sow and piglets have constant access to the corridor or outlet, which is partly covered and covered by straw in the entire lying area. The only available watering place and the hay rack are installed in the outlet. The feeding area can only be reached through the outlet. The feeding trough is placed in the control corridor.(Figure 1).

\section{Working time measurements}

A methodical approach by Auernhammer (1976) was used for the analysis of the pen-related work. With this approach, the total work and the different activities of the piglet production were broken down into tasks and work elements, and their influencing parameters were determined. The smallest unit was represented by the work item. For determining the smallest possible work elements (Centiminutes) of routine, special and monitoring work, a Pocket PC with the time measurement software ORTIMb3 was used. Through the timekeeper, influencing factors such as distance, litter size, and feed and straw amounts used were recorded by on-site measurements (Riegel et al., 2006). The results were tested for randomness, normal distribution and outliers, and the epsilon and variance coefficient values were used for the evaluation of the accuracy of the estimates of the mean values of the population. The standard times and influencing parameters were used to determine the labor time required for each working tasks per passage and year by modeling them in the spreadsheet program.

\section{Results and discussion}

Standard times were collected for elements of the tasks and subtasks of routine and special work for the suckling period, which lasted 21 days for each period..

\section{Routine work}

The work process of feeding included the subtasks of fetching and rationing the feed. For feed fetching, the labor input was $0.17 \mathrm{MPmin}$ (Man power minutes) per pen and day. This matches the data reported in existing literature on other farrowing crate systems and could be reduced further by shortening the transport routes (Weichselbaumer, 1996; Riegel et al., 2006). The labor time requirement for the distribution was $0.46 \mathrm{MPmin}$ per pen and day. In other systems similar time input exists (Riegel et al., 2006) only WEICHSELBAUER (1996) reports slightly lower input values. For feeding, the labor input was 0.63 MPmin per pen and day. WEICHSELBAUER (1996) reports for other crate systems a value of 0.4 MPmin per crate and day. This could be explained by shorter transport routes and the absence of the protective grid at the feeding trough, which requires a slower allocation of feed in order to avoid loss and pollution in the feed trough environment. The task of the daily health check was carried out after feeding and included examining the sow in the pen and the piglets in the piglet nest. The labor time required for the health check of sow and piglets was 0.37 MPmin per pen and day, although the actual check lasted 4 MPcmin (Man power centiminutes) (2.4 MPsec (Man power seconds)) for the sow pen as well as the piglet nest. This is a labor requirement which is influenced by the construc-

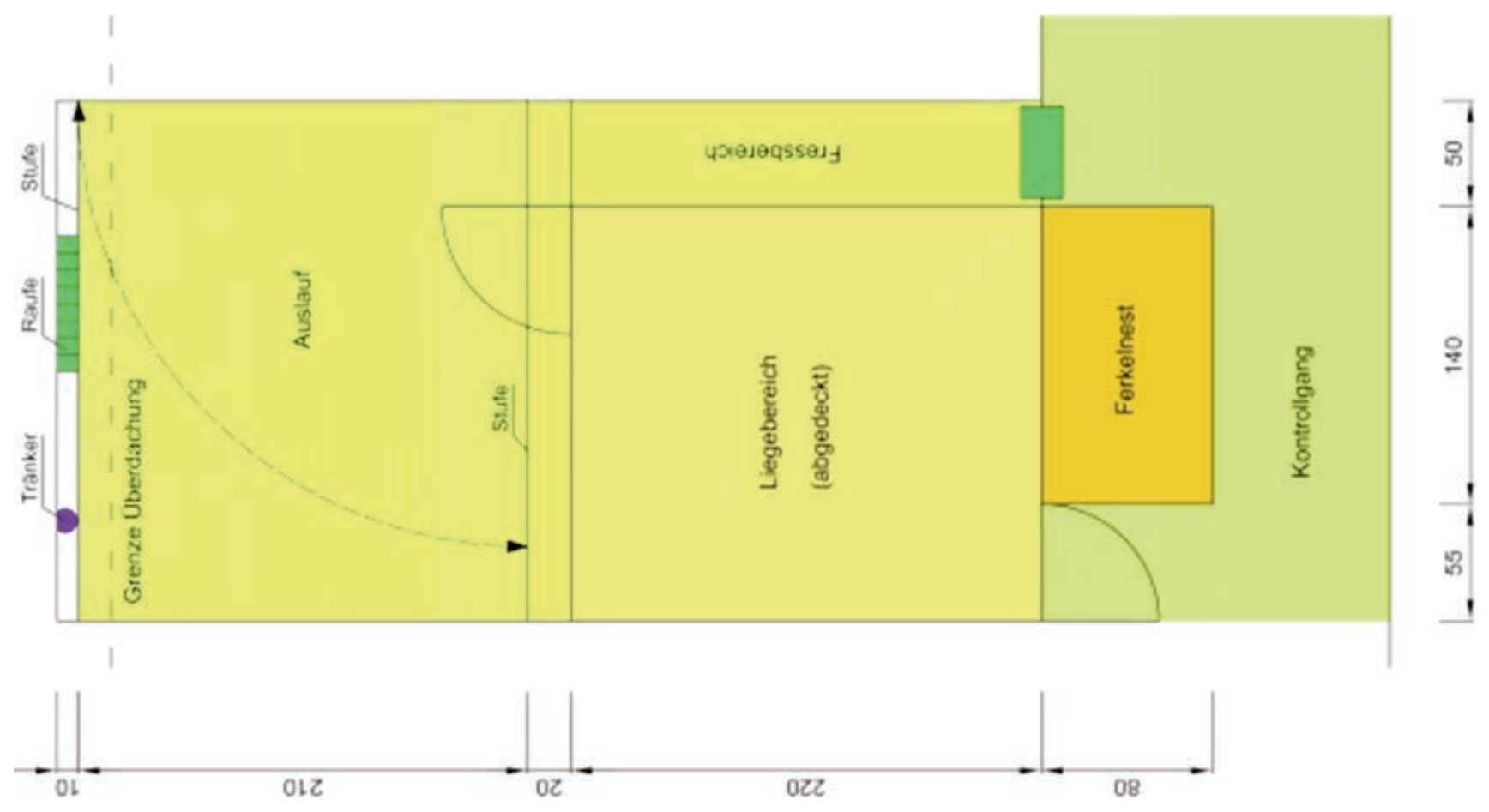

Figure 1. Schematic representation of the farrowing pen of Wels, including dimensions 


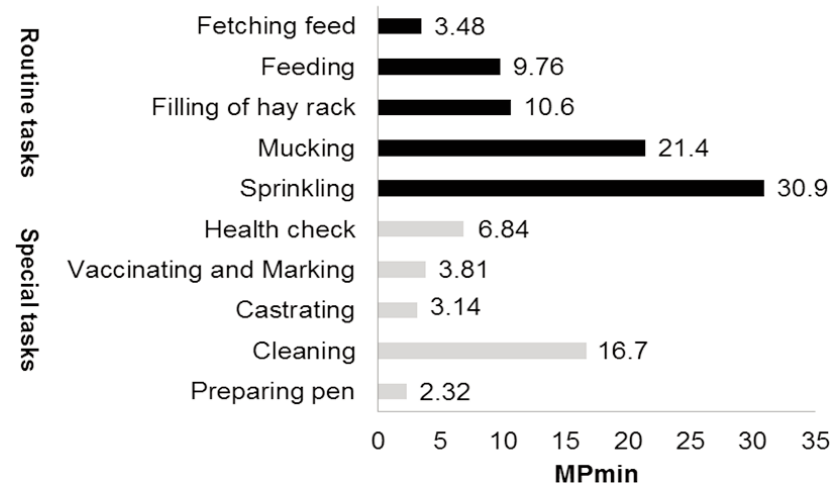

Figure 2. Working times of tasks of a suckling cycle in MPmin

tion design. For example, in the FAT2 or other crate systems it is only partially necessary. The lower time input for the health check of sows in crate systems (2.81 MPcmin, MPsec 1.69) is caused by the better overview of the crate which is not limited by high walls and a lid, but it cannot be avoided when sows are kept without fixation under outdoor climate conditions (Quendler et al., 2010).

The mucking out of the manure of the outlet was done immediately after feeding, while the sow was kept in the feeding area. Since it was carried out with a Hoftrac, it was necessary to open the screen doors. The labor requirement for daily mucking amounted to 1.02 MPmin per sow and day, which is similar to the requirement for FAT2 pens (Riegel et al., 2006). The lying area of sow and piglets had never been mucked during one suckling period, because the outlet area was recognized as manure place.

The sprinkling with straw of the outlet was done immediately after mucking. It consisted of the subtasks of fetching the straw, sprinkling, and closing the screen doors. The labor time required for the task sprinkling was 1.47 MPmin per pen. It is higher than the requirements of other crate systems which have a smaller sprinkling surface, smaller sprinkling amount, and a shorter distance to the straw storage (Weichselbaumer, 1996, 1999). Sows were supplied with hay not only for feeding purposes, but also for the promotion of their species-specific activities. The filling of the hay rack consisted of the subtasks of fetching and allocating the hay into the rack. The time requirement for transportation was $36 \mathrm{MPcmin}$ (21.6 MPsec) and for allocating the hay $14.6 \mathrm{MPcmin}$ (8.75 MPsec). A reduction of the time required would be possible if the distance between rack and hay storage was smaller and if a hay bale was transported while fetching the last straw delivery. The labor time required for routine work was 3.99 MPmin per day and pen, and 83 MPmin per passage (21 days). According to Quendler et al. (2010), the labor requirement for the routine work of FAT2 pen was 1.47 MPmin per sow and day. This lower requirement was achieved with a stock of 100 lactating sows, having no outlet, with semi-automated feeding, and sprinkling and mucking only twice a week. Riegel et al. (2006) determined a labor input of 3.3 to $4.9 \mathrm{MPmin}$ per pen and day of high to low mechanization for group sizes of 40 sows. According to this comparative study, the daily working time requirement for the farrowing pen of Wels can be considered to be low.

\section{Special work}

The special work included the tasks of vaccinating, marking with ear tags, castrating piglets, and cleaning and preparing the pen for the next sow or passage. Vaccinating and marking with ear tags were done two days after birth, after feeding, as the sow was at the feeding trough and the piglets in the nest. The labor time needed for piglet handling was 120 MPcmin, for treatment 179 MPcmin, and for marking 82 MPcmin per pen. The treatment and marking of 12 piglets required $3.81 \mathrm{MPmin}$, which is similar to values of other studies (Riegel et al., 2006). The optimization options are limited to opening and locking the nest lid. Castration was performed in the first week. It included the subtasks of piglet handling (120 MPcmin), administering painkillers (33 MPcmin), and castration (161 MPcmin). The labor time requirement of this task was 0.52 MPmin per piglet, or 3.14 MPmin per pen. Cleaning of the pen after one passage (suckling cycle) included the subtasks of mucking and cleaning. The labor time inputs for sweeping the pen and the piglet nest were 46.4 MPmin (27.8 MPsec) per $\mathrm{m}^{2}$, or 2.32 MPmin per pen. Washing pen, nest, and feeding place, which had an area of $5.4 \mathrm{~m}^{2}$, required a working time of $130 \mathrm{MPcmin}$ (78 MPsec) per $\mathrm{m}^{2}$, or 7.02 MPmin per pen. Cleaning the manure area included the subtasks of opening the screen doors and washing the outside area. The labor time required for cleaning the pen (mucking and washing) was 16.7 MPmin per pen and was the largest labor activity-related time requirement. The time required for sweeping out the pen area was higher than in other studies and was caused by the small nest opening, which is a hindrance during this work process. The reduced labor input for washing one square meter of the pen area corresponded with the lower degree of contamination compared with other systems (Riegel et al., 2006; Quendler et al., 2007). The task of preparing the crate for the next sow included the subtasks of fetching straw and sprinkling. Fetching the straw took 1.67 MPmin and sprinkling 0.66 MPmin. The labor time required for the preparation of the crate was 2.32 MPmin. A reduction of the labor time requirements would be possible if the straw storage was closer.

\section{Working requirements of the farrowing pen of wels}

The labor input of the farrowing pen of Wels was 109 MPmin per passage, which corresponded to three weeks. It consisted of $76.1 \%$ of routine work and $23.9 \%$ of special work. (Figure 2)

For 2.1 litter per year, the labor time requirement per sow and year is 3.81 MPh (Man power hours). Riegel et al. (2006) showed a value of $4.9 \mathrm{MPh}$ for sow and piglets per year in the FAT2 pen at a herd size of 30 animals during a 4-week production cycle with low manual labor input. It increased to 5.9 MPh per sow and year for herd sizes of 20 animals. This would represent a working time requirement of $4.79 \mathrm{MPh}$ per sow and year of a 4-week production cycle for the pen of Wels. According to Quendler et al. (2010), the working time requirement for the pen of Wels is slightly higher $(+9.1 \%)$ than for the FAT2 pen used for a large herd size of breeding sows ( 606 sows). The lower labor input for a FAT2 pen can be explained by this pen being managed with a semi-automated feeding system and not having the outlet mandatory for organic piglet production. Overall, the low working time requirement of the pen of Wels is achieved because mucking and sprinkling of the sow pen and piglet nest are unnecessary and mucking and sprinkling of the outlet are performed with machinery.

\section{References}

Auernhammer H. 1976. Eine integrierte Methode zur Arbeitszeitanalyse. KTBL-Schrift. 203:95.

Hagmüller W., Preinerstorfer A. 2010. Freies Abferkeln im Außenklimastall - ist das möglich? Der fortschrittliche Landwirt. 24:20-22.

Quendler E., Martetschläger R., Baumgartner J., Boxberger J., Schick 
M. 2007. Arbeitszeitbedarfsunterschiede von verschiedenen Abferkelbuchten. 8. Tagung Bau, Technik und Umwelt, Bonn, Deutschland, pp 318-323.

Quendler E., Podiwinsky C., Martetschläger R., Helfensdörfer V., Baumgartner J., Winckler C., Boxbrger J. 2010. Arbeitswirtschaftliche und ökonomische Analyse verschiedener Abferkelsysteme, Die Bodenkultur. 61(1):29-36.

Riegel M., Schick M. 2006. Arbeitszeitbedarf und Arbeitsbelastung in der Schweinehaltung - Ein Vergleich praxisüblicher Systeme in Zucht und Mast. FAT Bericht. 650:5-8.
Statistik Austria 2011. Available from:http:/www.statistik.at/web_de/statistiken/land_und_forst-wirtschaft/ viehbestand_tierische_erzeugung/tierbestand/index.html\#index2, Accessed: April 2013.

Weichselbaumer L. 1996. Ermittlung des Einstreu- und Arbeitszeitbedarfes von Einzel- und Gruppenhaltungssystemen für ferkelführende Sauen. Diplomarbeit, Universität für Bodenkultur, Österreich.

Weber R., Keil N., Fehr M., Horat R. 2006. Ferkelverluste in Abferkelbuchten - Ein Vergleich zwischen Abferkelbuchten mit und ohne Kastenstand. FAT Bericht. 656:6. 